\title{
On the Mechanism by Which Phenytoin Blocks Post-tetanic Potentiation at the Frog Neuromuscular Junction ${ }^{1}$
}

\author{
MICHAEL E. SELZER, ${ }^{2}$ GABY DAVID, AND YOEL YAARI \\ Department of Physiology, The Hebrew University-Hadassah Medical School, Jerualem 91010, Israel
}

\begin{abstract}
Post-tetanic potentiation (PTP) was elicited at the frog sartorius and cutaneous pectoris neuromuscular junctions. $\mathbf{A}$ 30-sec, 30-Hz tetanus produced a 2- to 3-fold post-tetanic increase in endplate potential (EPP). In surface-recorded responses this PTP decayed in a double exponential way with time constants of $12.7 \mathrm{sec} \pm 2.4$ (SEM) and $146.8 \mathrm{sec} \pm$ 36.6. In acute experiments 0.2 to $0.8 \mathrm{~mm}$ phenytoin (5,5diphenylhydantoin, DPH) dramatically and reversibly reduced the early component. The late component was also reduced, although to a lesser extent and often not reversibly. DPH reduced PTP even when there was no failure of the EPP during the tetanus. Thus, the DPH effect did not require a complete block of the presynaptic action potential. At longer exposures and higher DPH concentrations EPP failures did develop, and this was associated with a more profound suppression of PTP.

PTP was also elicited in tetrodotoxin (TTX)-containing solutions using electronic stimulation of nerve terminals to elicit transmitter release. This PTP had a much shorter duration (about $30 \mathrm{sec}$ ) than that seen in normal Ringer's solution and was followed by depression of EPP amplitudes. Thus, sodium entry into nerve terminals enables a mechanism which greatly prolongs PTP. DPH had no effect on PTP in TTX. These results, together with others in the literature, suggest that the reduction of PTP by DPH involves a graded reduction of sodium influx into nerve terminals during high rates of axon stimulation. The development of all-or-none failures of the presynaptic action potential results in even greater suppression of PTP.
\end{abstract}

The anticonvulsant drug phenytoin (5,5-diphenylhydantoin, DPH) is known to block post-tetanic potentiation (PTP) at several synapses (Esplin, 1957; Raines and Standaert, 1966; Selzer, 1978). This is thought to be relevant to its therapeutic action because, during epileptic activity, cortical neurons fire at very high frequencies (Matsurnoto and Ajmone-Marsan, 1964; Prince, 1968; Dichter and Spen-

Received January 2, 1985; Revised April 18, 1985; Accepted May 14, 1985

\footnotetext{
${ }^{1}$ This work was supported by the United States-Israel Binational Science Foundation, Jerusalem, Israel, and by United States Public Health Service Fogarty Senior International Fellowship IF86 TW00697 to M. E. S. Y. Y. is a Bat-Sheva de Rothschild Scholar; G. D. is a Foulkes Fellow. We are grateful to Dr. R. Rahamimoff for advice and help with computer analysis of data and to M. Haran for skillful technical assistance.

${ }^{2}$ To whom correspondence should be sent, at the Department of Neurology, Hospital of the University of Pennsylvania, Philadelphia. PA 19104.
}

cer, 1969; Matsumoto et al., 1969; Ward, 1969) and thus subject each other to tetanic potentiation (TP) and PTP.

The mechanism by which DPH blocks PTP is still unknown. Several laboratories have described drug-induced elevations of threshold for activation of the sodium action potential or partial blockade of sodium influx into neurons (Korey, 1951; Lipicky et al., 1972; Pincus, 1972; Ayala et al., 1977; Newman and Frank, 1977; Schwarz and Vogel, 1977; Selzer, 1979; Connors, 1981; Courtney and Etter, 1983; McLean and Macdonald, 1983; Matsuki et al., 1984; Willow et al., 1984). Others have demonstrated that DPH can interfere with voltage-dependent calcium entry (Pincus and Lee, 1973; Sohn and Ferrendelli, 1973; Hasbani et al., 1974; Tuttle and Richelson, 1979; McLean and Macdonald, 1983). Both ionic mechanisms have been implicated in the genesis of PTP. Thus, DPH could act by blocking the invasion of the nerve terminal by high frequency action potentials (McLean and Macdonald, 1983; Matsuki et al., 1984; Yaari et al., 1985), by reducing the accumulation of sodium by the nerve terminal, or by reducing the entry of calcium into the nerve terminal. The latter could be secondary to a reduced action potential amplitude or to a reduction in the voltage-dependent calcium conductance. It is also possible that DPH affects PTP by intracellular mechanisms which do not involve alterations of ionic conductances (De Lorenzo, 1980).

In order to distinguish among the above hypotheses, we have studied the action of DPH at the neuromuscular junction, where PTP has been most thoroughly characterized, both with regard to its basic phenomenology (Feng, 1941; Hubbard, 1963; Magleby and Zengel, 1976a, b) and its ionic mechanisms (Rosenthal, 1969; Weinreich, 1971; Erulkar and Rahamimoff, 1978; Lev-Tov and Rahamimoff, 1980; Meiri et al., 1981). The results suggest that DPH blocks PTP even without blocking action potential invasion into nerve terminals during tetanic stimulation and that much of this effect is mediated through the reduction of sodium entry into stimulated nerve terminals.

\section{Materials and Methods}

Preparation. Experiments were performed on the sartorius and cutaneous pectoris neuromuscular junctions of the frog Rana ridibunda. No significant differences were noted in the action of DPH at these two muscles.

Solutions. Dissection was performed in a standard frog Ringer's solution (115.6 $\mathrm{mm} \mathrm{NaCl}, 2 \mathrm{mM} \mathrm{KCl}$, and $1.8 \mathrm{mM} \mathrm{CaCl}_{2} 2 \mathrm{mM}$ Tris buffer, $\mathrm{pH} 7.4$ ). In order to study PTP, quantal content was reduced by adding $4 \mathrm{mM} \mathrm{Mg}$ and reducing $\mathrm{Ca}$ to 0.4 to $0.8 \mathrm{~mm}$. Isotonicity was maintained by substitution for $\mathrm{NaCl}$. DPH (Sigma Chemical Co.) was dissolved first in a few drops of $0.1 \mathrm{M}$ $\mathrm{NaOH}$ and then added to Ringer's solutions; $\mathrm{pH}$ was then readjusted to 7.4. Effects on PTP were seen within $1 \mathrm{hr}$ at DPH concentrations of 0.2 to 0.8 $\mathrm{mm}$. In some experiments, action potentials were blocked by addition of tetrodotoxin (TTX) at $10^{7}$ to $10^{-6} \mathrm{gm} / \mathrm{ml}$ to a normal Ringer's solution.

Stimulation. The motor nerve was stimulated by $0.05-\mathrm{msec}$ pulses at resting frequencies of 0.2 to $0.5 \mathrm{~Hz}$. Tetani of frequencies from 20 to $50 \mathrm{~Hz}$ and durations of 10 to $40 \mathrm{sec}$ were delivered at intervals of 10 to $30 \mathrm{~min}$. 
These parameters were selected so as to maximize potentiation while avoiding as much as possible long-term depression of endplate potentials (EPPs) and changes in frequency-dependent behavior of synapses which are seen following frequent trains of stimuli (Magleby and Zengel, 1976b). When trains of fewer stimuli were given, the intervals between trains were shorter. PTP was determined by returning to pre-tetanus frequency heginning 1.5 to $3 \mathrm{sec}$ after the tetanus. In some experiments the early time course of PTP was determined by stimulating at $1.5-\mathrm{sec}$ intervals for the first $20 \mathrm{sec}$.

In TTX, nerve terminals werc stimulated electrotonically (Katz and Milcdi, 1967). The nerve was dissected to its point of entry into the connective tissue of muscle. It was then drawn into a suction electrode through which 1 -msec square pulses of anodic current were applied. A normal Ringer's solution was used and the size of the pre-tetanus EPP was regulated by varying the amplitude of the stimulus. The stimulus artifact was reduced by recording differentially, using a second microelectrode placed extracellularly near the endplate. Nevertheless, it was not possible to completely eliminate the artifact, which generally reduced slightly the apparent amplitude of the EPP. Since this artifact was symmetrical in reversed polarities, it was recorded using cathodic current for each new stimulus strength, and its amplitude at the time of peak EPP was determined. This was of the order of $0.4 \mathrm{mV}$, which was added to each EPP amplitude in subsequent calculations in order to avoid overestimates of potentiation when the pre-tetanic EPP was very small.

Recording. Both intracellular and surface recording techniques were used The latter had the advantage that currents of several endplates were recorded simultaneously, thus reducing the fluctuations in EPP amplitudes which obscure the time course of PTP in intracellular recordings. The surface electrode was adapted from the design of Magleby (1973). It consisted of a hollow polyethylene tube of $0.8 \mathrm{~mm}$ internal diameter with a $1-\mathrm{mm}$ flange at the end. The perfusion solution was sucked into the electrode through a flexible cannula, the distal end of which was set at a fixed height (about 3 $\mathrm{cm}$ ) below the level of the muscle surface. This created a gentle calibrated suction at the tip of the electrode by which it could be applied to the muscle surface at points of maxirnum sign ral amplitude. The electrode was removed from the surface following each change in bath composition and the new solution was allowed to fill the core. The surface electrode was lifted and lowered on a micromanipulator. Repeated measurements of groups of steady-state EPPs after lifting and lowering several times showed that the means did not vary by more than about $7 \%$ of the average EPP amplitude.

Intracellular microelectrodes were filled with $3 \mathrm{M} \mathrm{KCl}$ and had tip resistances of 5 to 15 megohms. Signals were led through a high impedance preamplifier, recorded on FM tape, and analyzed either by a PDP-MINC computer or with a Nicolet digital oscilloscope.

Statistical evaluation of PTP. The decay of PTP was analyzed using the assumption of a double exponential time course. We have used the terminology of Magleby and Zengel (1976b), "augmentation" $(A)$ for the early phase and "potentiation" $(P)$ for the late phase. These functions are defined as the proportional increase in the response above pre-tetanus control. Thus, $P=V-V_{c} / V_{c}$ during the late monotonic decay, where $V$ is the EPP amplitude and $V_{c}$ is the mean pre-tetanus control amplitude. $A=V-V_{c} / V_{c}-P$ during the early phase. Ideally, during the early phase of decay $P$ should be determined by regression of $\log \left(V-V_{c} / V_{c}\right)$ on time. This was sometimes difficult because fluctuations in $V$ resulted in many values less than $V_{c}$, so that this log could not be calculated. Fortunately, in the range of the observed values, $\log V$ behaved linearly with respect to time, and calculations based on regression of the $\log V$ versus time did not differ significantly from those based on the regression of $\log \left(V-V_{c} / V_{c}\right)$ versus time. Thus, $P$ was determined by linear regression of the log $V$ versus time curve and $A$ was calculated trom the ditterence between the observed $V$ and that calculated from the extrapolated $P$ at early times (generally less than $30 \mathrm{sec}$ ). If, during the early phase of PTP, values of $V$ fluctuated below this extrapolated value, a moving bin-averaging technique, with a bin of 3 points and a bin of 1 , was applied to reduce fluctuations and thus avoid the impossibility of finding the $\log$ of a negative number. If fluctuations were still too great the parameter could not be calculated and was omitted from Table 1.

\section{Results}

Overview of DPH Effects. The salient effects of DPH on the EPP are illustrated in the surface recordings of Figure 1. As previously reported (Yaari et al., 1977; 1979), under conditions of low quantal release DPH produces a variable and small change in EPP amplitude, usually a reduction (Fig. $1 \mathrm{~A}$ ). During a $30-\mathrm{sec}, 30 \mathrm{~Hz}$ tetanus the EPP amplitude increased 4- to 9-fold. After $1 \mathrm{hr}$ of exposure DPH dramatically reduced this tetanic potcntiation (Fig. $1 B$ ). This effect
TABLE ।

Effects of $0.2 \mathrm{~mm} \mathrm{DPH}$ on parameters of PTP in experiments using surface-recorded EPPs

Values are means \pm SEM. Values for DPH were determined after 1 to 2 $\mathrm{hr}$ of exposure. Values for Wash were determined after $2 \mathrm{hr}$ in normal Ringer's.

\begin{tabular}{ccccc}
\hline & $\tau_{a}(\mathrm{sec})$ & $A_{o}$ & $\tau_{p}(\mathrm{sec})$ & $P_{\mathrm{o}}$ \\
\hline Control & $12.7 \pm 2.4$ & $0.62 \pm 0.16$ & $146.8 \pm 36.6$ & $0.77 \pm 0.14$ \\
& $n=6$ & $n=6$ & $n=5$ & $n=6$ \\
DHH & $18.8 \pm 4.9$ & $0.19 \pm 0.07^{a}$ & $414.6 \pm 146.6$ & $0.35 \pm 0.04^{\circ}$ \\
& $n=6$ & $n=10$ & $n=10$ & $n=10$ \\
Wash & $9.1 \pm 1.9$ & $0.53 \pm 0.18$ & $179.0 \pm 61.5$ & $0.19 \pm 0.05^{a}$ \\
& $n=6$ & $n=8$ & $n=7$ & $n=8$ \\
\hline
\end{tabular}

${ }^{a} p<0.05$

${ }^{b} p<0.01$

A Pre-Tetanus B Tetanus C Post-Tetanus

Control

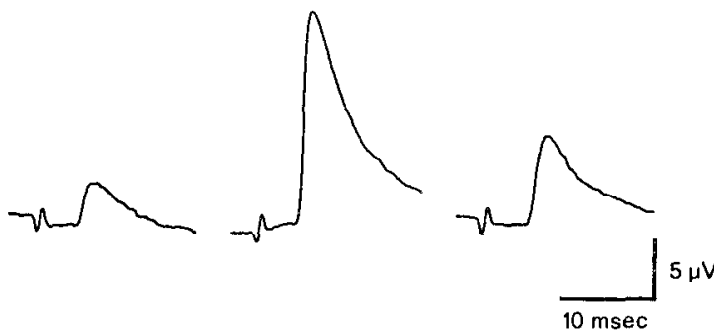

$\mathrm{DPH}$

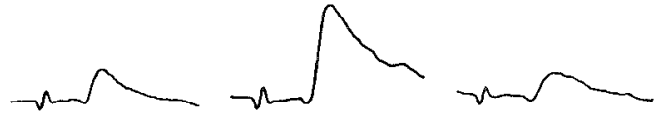

Wash

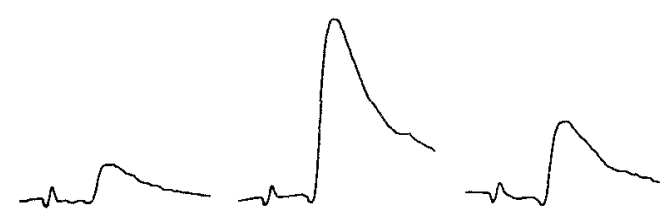

Figure 1. Effects of $0.2 \mathrm{~mm} \mathrm{DPH}$ on the frequency-dependent behavior of the EPP. Six surface recordings were averaged for EPPs before and during the peak of a $30-\mathrm{Hz}, 30-\mathrm{sec}$ tetanus. The post-tetanic responses are averages of the first three EPPs beginning $1.5 \mathrm{sec}$ after the tetanus. $A$, DPH produced a small, reversible reduction in EPP amplitude. $B$, Reversible reduction in TP was produced by DPH. C, Reversible reduction in PTP was produced by $\mathrm{DPH}$. Recordings in DPH and Wash were after $1 \mathrm{hr}$ exposure.

has been described in more detail elsewhere (Selzer et al., 1984) and will not be discussed here. Immediately after the tetanus the EPP was increased 2- to 4 -fold. DPH dramatically reduced this PTP (Fig. 1C). Reversal of DPH effects required 1 to $2 \mathrm{hr}$ of wash.

Time Course of PTP. The decay of PTP in these experiments had a time course similar to that described by Magelby and Zengel (1976a). It decined rapidly over the first 10 to $20 \mathrm{sec}$ and then more slowly for about $3 \mathrm{~min}$ (Fig. 2). This double-phased time course could also be seen in intracellular recordings, especially if two or more tetani were averaged so as to reduce the impact of fluctuations in EPP amplitude, as in Figure 3.

PTP decayed with a double exponential time course (Fig. 4). The time constant $\left(\tau_{a}\right)$ of the early component (augmentation $(A)$ of Magleby and Zengel, 1976a) averaged $12.7 \mathrm{sec}$, whereas the average time constant $\left(\tau_{\rho}\right)$ for the late component (potentiation, $P$ ) was $146.8 \mathrm{sec}$ (Table I). These time constants are described phenomenologically, without any assumption as to their mechanistic interpretation.

Effect of DPH on PTP. Addition of DPH was followcd by a 


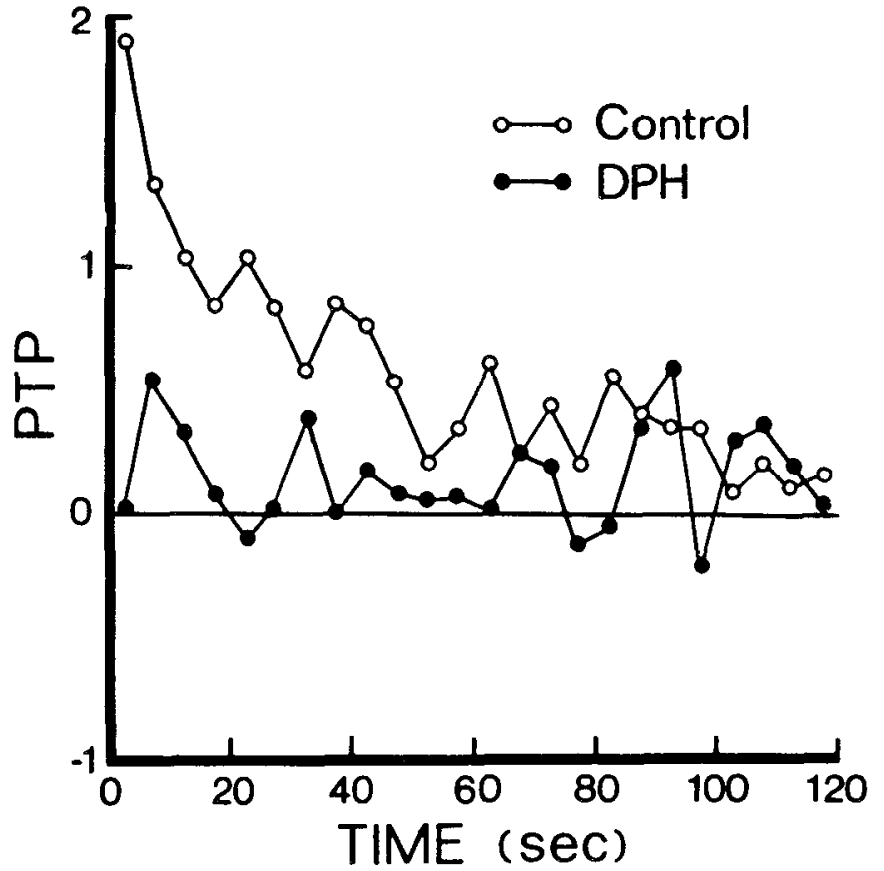

Figure 2. Reduction of PTP by $0.2 \mathrm{~mm} \mathrm{DPH}$ for $1 \mathrm{hr}$. The time course of PTP is compared for surface-recorded EPPs in DPH and control Ringer's solution. Note the pronounced depression of the early phase of PTP in DPH.

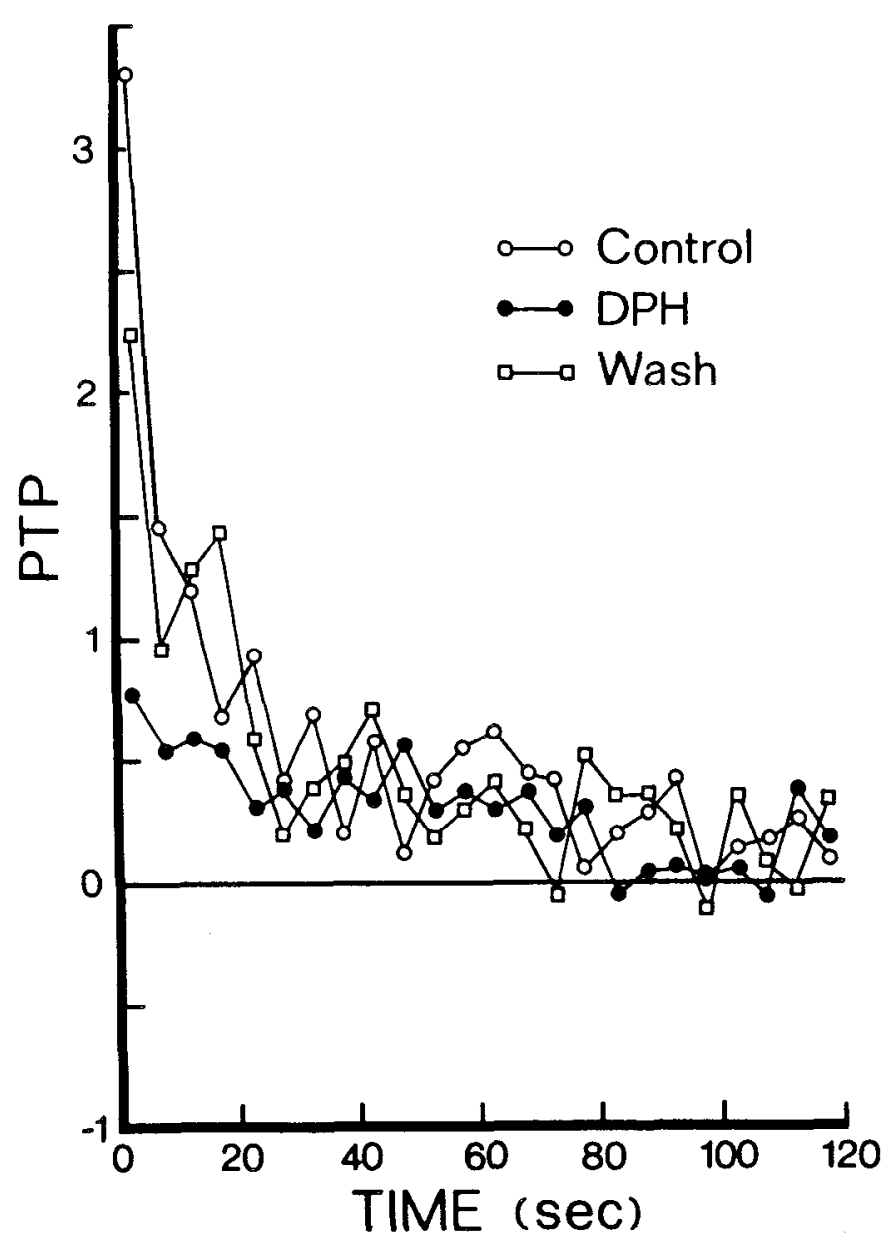

Figure 3. Effects of $0.2 \mathrm{~mm}$ DPH on PTP of intracellularly recorded EPPs. Each curve represents the average of two post-tetanic series.
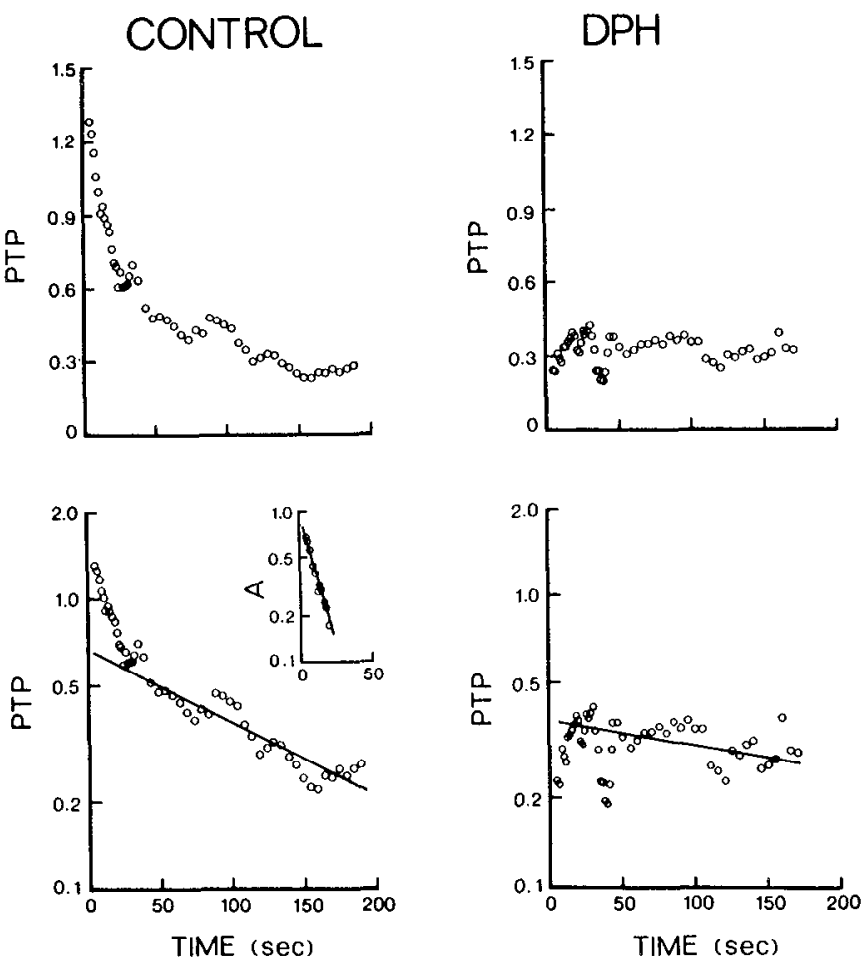

Figure 4. Effect of $0.2 \mathrm{~mm}$ DPH on the time course of PTP. The lower graphs are similogarithmic and demonstrate the double exponential decay of PTP. Note that DPH eliminated the early component of PTP (augmentation, $A$ ) and also reduced the maximal amount of the late component of PTP (potentiation, $P$ ). The time course of $A$, shown in the inset of the lower left graph, was derived by extrapolating the value of $P$ to time 0 , subtracting the value of $P$ from PTP at each point, and plotting the log of this value against time. This gives values for $A$ on the assumption that $A$ and $P$ are additive. The date for all graphs represent averaged data from four surface-recorded series each. The earliest DPH tetanus was after $1 \mathrm{hr}$ of exposure.

reduction of both the early and late components of PTP (Fig. 4). However, as previously described (Magleby and Zengel, 1976b), $P$ tended to decrease with repeated tetani. Thus, the reduction in this component following DPH was often not reversible (Table I), and it is not clear how much of this reduction was due to the action of $\mathrm{DPH}$. By contrast, the reduction of the early component, $A$, was dramatic and reversible (Fig. 3, Table I). The extrapolated value of $A$ to the beginning of the post-tetanus period $\left(A_{o}\right)$ fell from an average of 0.62 in control solutions to 0.19 in $\mathrm{DPH}$ and returned to 0.53 after an hour or more of wash (Table I).

The time constants of decay of $A$ and $P$ were both reversibly increased, although variability in these values was great and the difference did not reach statistical significance at the 0.05 level (Table I).

The effect of DPH took a long time to develop and was often not maximal even after $2 \mathrm{hr}$. At higher concentrations the effect was seen sooner. When the preparation was bathed in $0.3 \mathrm{~mm}$ DPH for $2 \mathrm{hr}$, surface recordings showed an almost complete elimination of PTP, especially of the early component, which was often replaced by a post-tetanic depression (Fig. 5). Intracellular recordings under these conditions showed that the EPP often failed toward the end of the tetanus. Wash reversed the tetanic EPP block, and this was accompanicd by a return of PTP (Fig. 6). However, substantial reductions of PTP were seen under conditions of lower DPH concentrations and shorter incubation times in which the EPP never failed. Thus, DPH produced a reduction of PTP in the absence of block of the presynaptic action potential. Higher effective concentrations produced even greater depression of PTP, presumably by blocking the invasion of the nerve terminal by the action potential 
(Yaari et al., 1985), although this was not demonstrated directly in the present study.

Lack of effect on facilitation. When pairs of EPPs are elicited at intervals of less than $300 \mathrm{msec}$, the second is generally larger than

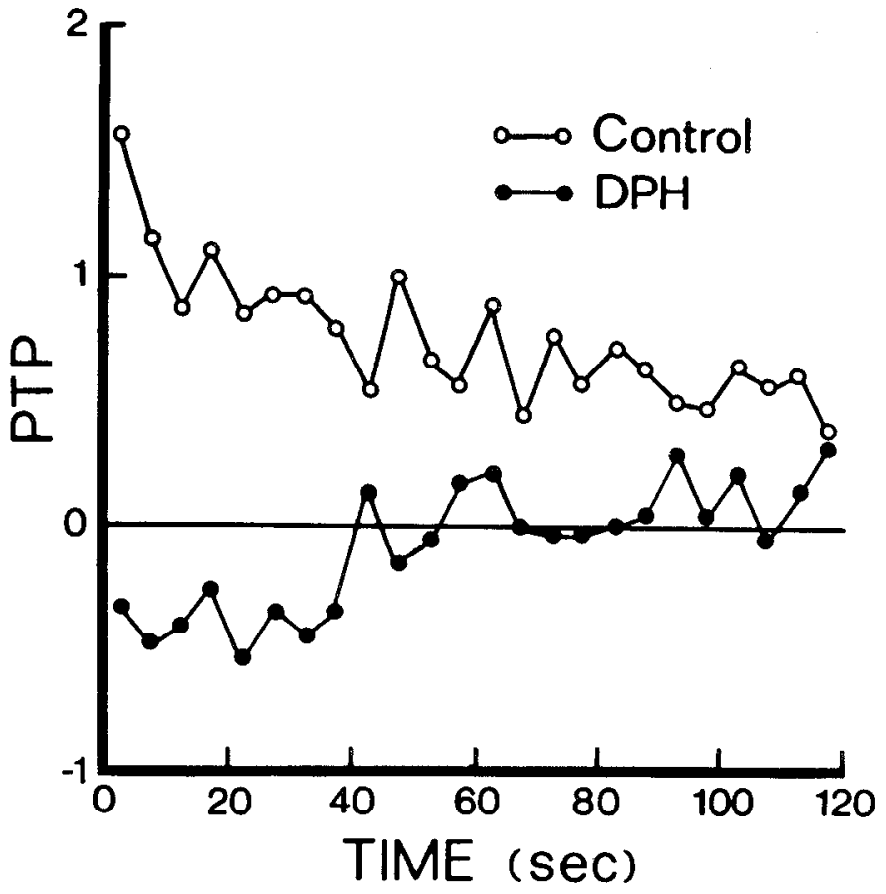

Figure 5. Replacement of PTP by post-tetanic depression in high concentrations of DPH. Surface EPPs were recorded after $4 \mathrm{hr}$ in $0.3 \mathrm{~mm} \mathrm{DPH}$ and in control solution. the first. This effect is called facilitation $(F)$ and is defined analogously to $A$ and $P$. It too has a double exponential time course (Mallert and Martin, 1967; Magleby, 1973; Younkin, 1974), but with decay time constants in the range of only 35 and $250 \mathrm{msec}$. DPH produced no effect on $F$ at interstimulus intervals of 10 to $100 \mathrm{msec}$ (Fig. 7).

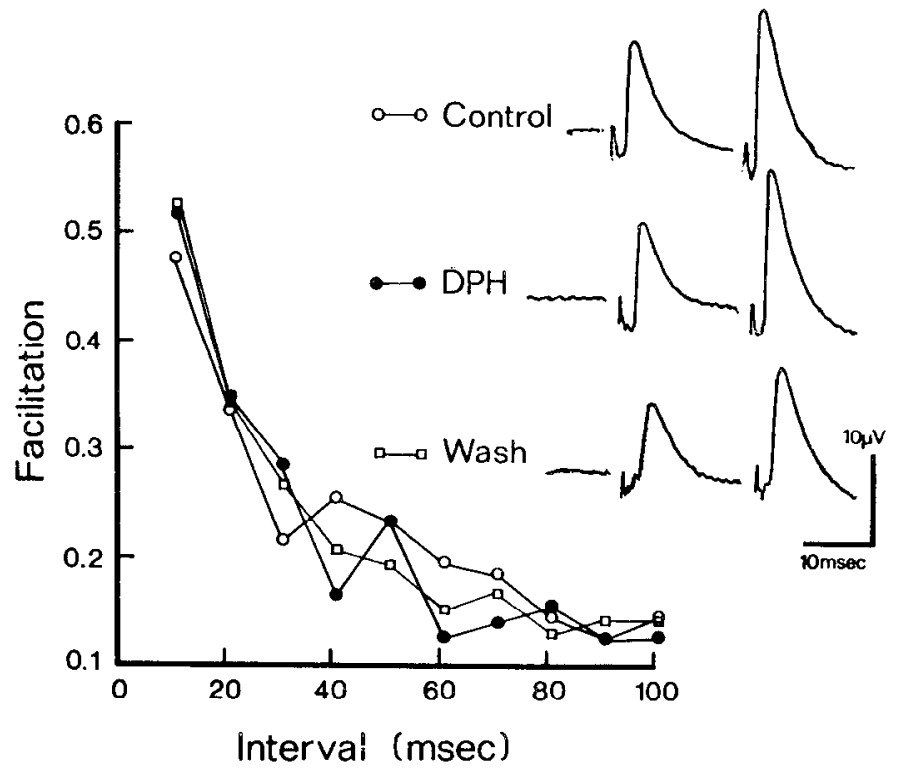

Figure 7. Lack of effect of $0.2 \mathrm{~mm}$ DPH on facilitation. The time course of facilitation was determined from pairs of surface-recorded EPPs at interstimulus intervals of 10 to $100 \mathrm{msec}$. Each point in the graph represents the average of 10 stimulus pairs. The inset demonstrates sample EPP pairs at the 20 -msec interstimulus interval. The tissue was exposed to DPH for $1 \mathrm{hr}$ before collecting DPH data.
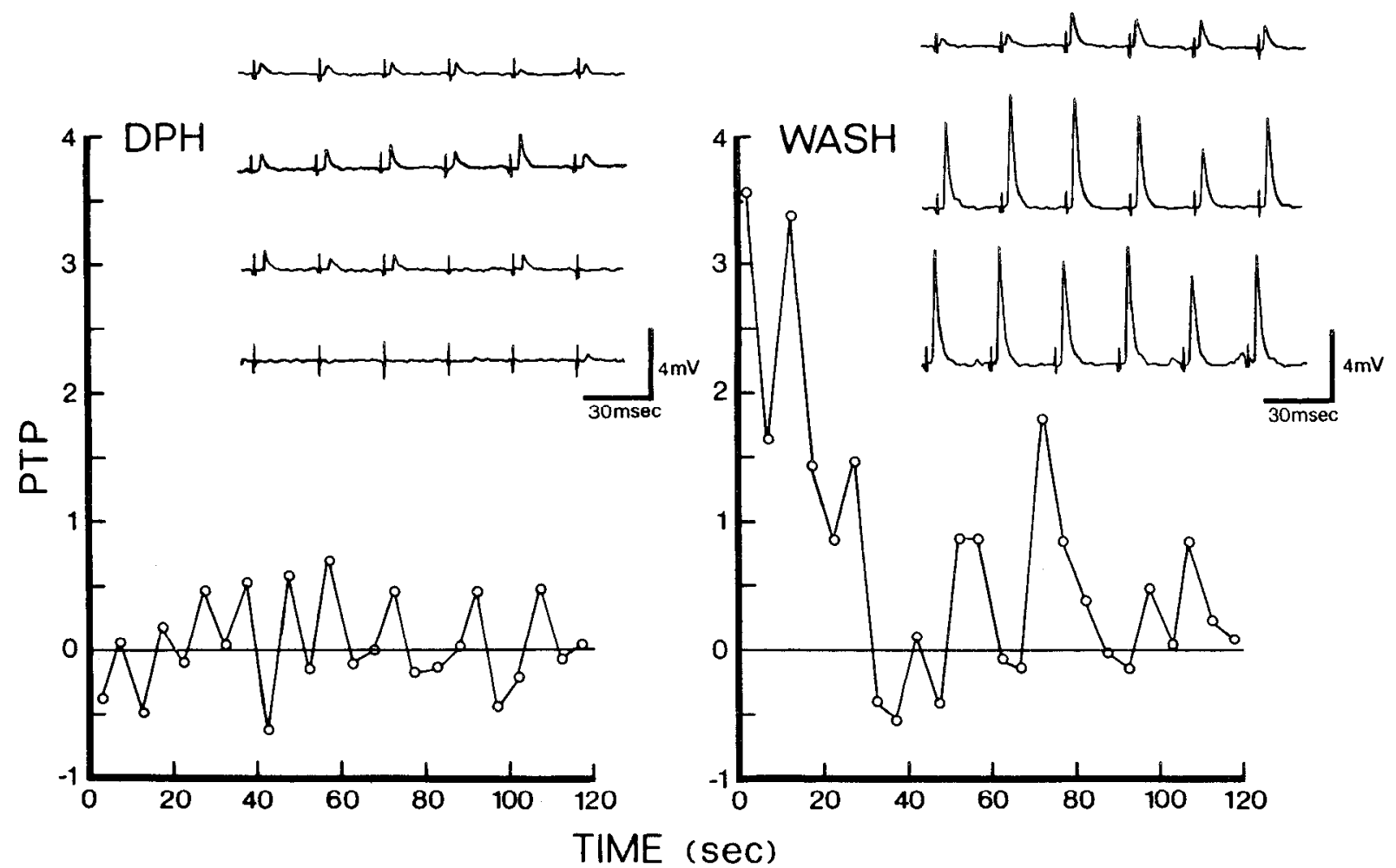

TIME (sec)

Figure 6. Development of neuromuscular block during tetanic stimulation in high concentrations of DPH. Left, the sartorius nerve-muscle preparation was bathed in $0.3 \mathrm{~mm} \mathrm{DPH}$ for $4 \mathrm{hr}$. Intracellularly recorded EPPs are sampled during the beginning, middle, and end of a 30- $\mathrm{Hz}, 30-\mathrm{sec}$ tetanus. Note the progressive increase in the frequency of fallure of transmission in the second hall of the lelanus. The lime course of PTP is plotted below. Note the depression seen early after the tetanus. Right, reversal of neuromuscular block after $2 \mathrm{hr}$ of wash. Note the return of PTP. 
PTP in TXX. In TTX, transmitter release was elicited by electronic stimulation. Under these conditions 30 to $50 \mathrm{~Hz}$ stimulation for 10 to 15 sec produced both TP and PTP. However, several differences were noted between the characteristics of PTP in IIX and regular Ringer's solution. In TXX synaptic depression was more prominent than in non-TTX solutions. This depression appeared during a tetanus lasting more than $10 \mathrm{sec}$ as a fall in TP and a delay in several seconds in the attainment of maximal levels of PTP. It also could be seen following PTP (Fig. 8). For this reason PTP was elicited better by $10 \mathrm{sec}$ tetani at $50 \mathrm{~Hz}$ than by longer tetani at $30 \mathrm{~Hz}$.

PTP had a much shorter time course in TTX than in non-TTX solutions. In TTX it never lasted longer than about $30 \mathrm{sec}$, whereas in normal Ringer's solution it could last 2 to $4 \mathrm{~min}$. Note that in Figure 8 the depression is miaximal by about 60 to $70 \mathrm{sec}$ after the tetanus. If the base line to which PTP decays is assumed to be the point of maximal depression, the duration of PTP in TTX would be just over $1 \mathrm{~min}$, which is still substantially shorter than its duration in regular Ringer's solution. Moreover, in TTX there appeared to be no division of the time course of PTP into an early and a late phase. The depression which followed PTP was reversible and lasted 2 to 3 min.

In contrast to its prominent effects with normal stimulation, DPH had little effect on PTP in TTX (Fig. 8).

\section{Discussion}

The present study shows that DPH dramatically redices PTP while not affecting the shorter time course process, facilitation. The effect of the drug was not seen in electrotonically stimulated preparations bathed in TTX, suggesting that the action of DPH may depend on, or be directed against, the voltage-dependent sodium influx. An alternate explanation for the present findings might be that DPH enhances a post-tetanic depression of junctional transmission. This seems unlikely because depression was most prominent in TTX-bathed preparations, on which DPH had no effect.

There is an apparent paradox in the pattern of PTP blockade, because DPH seems to have a more dramatic effect on the early component, augmentation, than on the late phase, potentiation. On the one hand, previous studies have suggested that the early component of PTP is selectively blocked by the absence of calcium in the bath (Erulkar and Rahamimoff, 1978; Lev-Tov and Rahamimoff, 1980 ) and that augmentation may represent a period of persistent increase in calcium conductance following high frequency stimulation (Lev-Tov and Rahamimoff, 1980). On the other hand, the present finding that TTX shortens the time course of PTP is consistent with the hypothesis that the potentiation phase may be secondary to

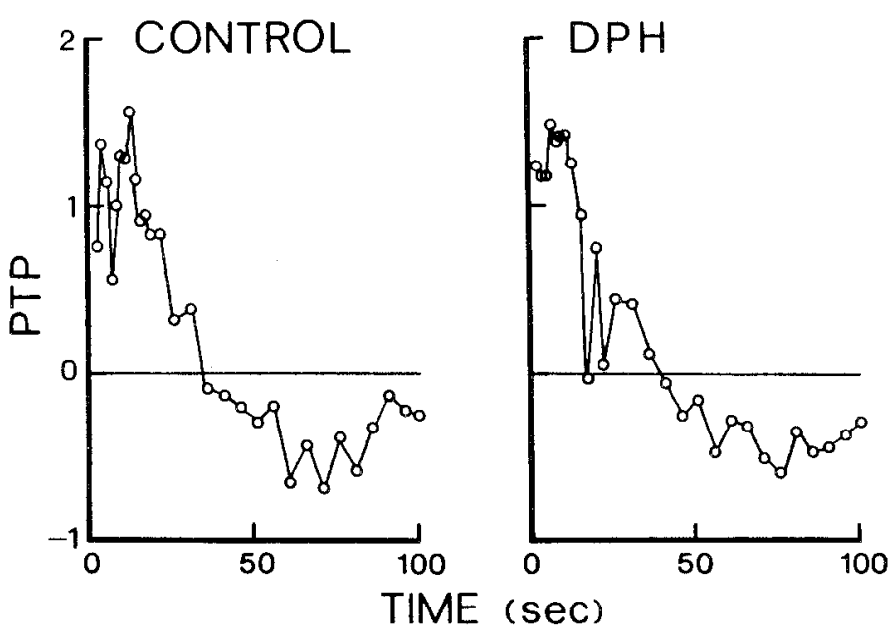

Figure 8. Lack of effect of $0.2 \mathrm{~mm}$ DPH for $1.5 \mathrm{hr}$ on PTP elicited in TTX by electrotonic stimulation of nerve terminals. Note the short time coursc of PTP in the absence of sodium entry into the nerve terminal and the depression of the intracellularly recorded EPP amplitude by 40 sec post-tetanus. intraterminal accumulation of sodium (Lev-Tov and Rahamimoff, 1980) and subsequent exchange of sodium for calcium in intracellular organelles (Carafoli and Crompton, 1978). Inspection of the time course of PTP observed in TTX by Weinreich (1971) also suggests a shorter duration than with normally stimulated nerve (Magleby and Zengel, 1976a). Therefore, the relatively greater reduction by DPH of augmentation in comparison to potentiation appears to be at odds with the notion that its primary effect depends on the presence of a sodium action potential in the motor nerve terminal.

One possible explanation for this paradox is the dependence of calcium entry on the amplitude of the action potential. Several studies have shown that DPH reduces the amplitude of the sodium action potential (Ayala et al., 1977; Selzer, 1979; Connors, 1981; McLean and Macdonald, 1983) by partially blocking the sodium conductance (Lipicky et al., 1972; Pincus, 1972; Newman and Frank, 1977 . Schwarz and Vogel, 1977; Courtney and Etter, 1983; Matsuki et al., 1984; Willow et al., 1984). By reducing the amplitude of the presynaptic action potential during and shortly after the tetanus, DPH could indirectly reduce the activation of the voltage-dependent calcium conductance and thereby reduce augmentation.

A second possible explanation may be related to the findings of Dudel (1984) that phasic transmitter release is influenced by the magnitude of terminal depolarization, independent of calciurr entry. Thus, the effect of DPH on augmentation may reflect action potential attenuation during and immediately following tetanic nerve stimulation, as recently demonstrated at the frog neuromuscular junction (Yaari et al., 1985).

Finally, it is possible that part of the apparent double exponential decay of PTP may be related to the cooperativity of intracellular calcium in the release of transmitter, resulting in a sigmoid-shaped curve of $\left[\mathrm{Ca}^{2+}\right]_{\circ}$ versus quantal release (Dodge and Rahamimoff, 1967). As accumulated cytosolic calcium is removed following the tetanus, the EPP amplitude would decay rapidly at first, and then more slowly. Any reduction in the accumulation of calcium, either by direct effect on the calcium conductance or indirectly, through a reduction of the sodium action potential, might have a greater effect on the early decay of PTP by acting on the steep portion of this curve (Parnas and Segal, 1980; Parnas et al., 1982). Howcver, the differential effects of divalent cations and of repetitive stimulation on various phases of facilitation and PTP (Zengel and Magleby, 1980 , 1981), and the selective reduction of the late phase of PTP by TTX shown in the present study, make it unlikely that such a mechanism can completely account for the double exponential rate of decay of PTP.

The above considerations show that the greater effect of DPH on augmentation than on potentiation is not inconsistent with a primary action to block the sodium channel. Recent evidence suggests that this sodium block is use and frequency dependent and graded in nature (Courtney and Etter, 1983; Matsuki et al., 1984; Adler et al., 1985; Yaari et al., 1985). Therefore, we propose that, at low stimulus frequencies in non-TTX solutions, DPH has little effect on the presynaptic action potential and therefore relatively little effect on transmitter release (Yaari et al., 1977, 1979). As the stimulus frequency increases, the action potential gets smaller, resulting in a lower cytosolic accumulation of sodium and, indirectly, also of calcium during the tetanus. The reduced accumulation of calcium, together with a temporary persistence of the reduction in amplitude of the presynaptic action potential, may explain the dramatic suppression of TP (Selzer et al., 1984) and augmentation by DPH. The reduction of sodium accumulation may suppress the potentiation phase of PTP.

\section{References}

Adler, E. M., Y. Yaari, G. David, and M. E. Selzer (1985) Frequency-dependent action of phenytoin on lamprey spinal axons. Brain Res., in press.

Ayala, G. F., S. Lin, and D. Johnston (1977) The mechanism of action of diphenylhydantoin on invertebrate neurons. I. Effects on the basic membrane properties. Brain Res 121: 245-258. 
Carafoli, E., and M. Crompton (1978) The regulation of intracellular calcium by mitochondria. Ann. N. Y. Acad. Sci. 307: 269-283.

Connors, B. W. (1981) A comparison of the effects of phenobarbital and diphenylhydantoin on the GABA sensitivity and excitability of adult sensory ganglion cells. Brain Res. 207: 357-369

Courtney, K. R., and E. F. Etter (1983) Modulated anticonvulsant block of sodium channels in nerve and muscle. Eur. J. Pharmacol. 88: 1-9.

De Lorenzo, R. J. (1980) Pheyntoin: Calcium- and calmodulin-dependent protein phosphorylation and neurotransmitter release. In Antiepileptic Drugs: Mechanisms of Action, G. H. Glaser, J. K. Penry, and D. M. Woodbury, eds., pp. 399-414, Raven Press, New York.

Dichter, M., and W. A. Spencer (1969) Penicillin-induced interictal discharges from the cat hippocampus. I. Characteristics and topographical features. J. Neurophysiol 32: 649-662.

Dodge, F. A., and R. Rahamimoff (1967) Cooperative action of calcium ions in transmitter release at the neuromuscular junction. J. Physiol (Lond.) 193: 419-432.

Dudel, J. (1984) Control of quantal transmitter release at frog motor nerve terminals. I. Dependence on amplitude and duration of depolarization. Pflugers Arch 402: 225-234.

Erulkar, S. D., and R. Rahamimoff (1978) The role of calcium ions in telanic and post-tetanic increase of miniature end-plate potential frequency. $\mathrm{J}$ Physiol. (Lond.) 278: 501-511

Esplin, D. W. (1957) Effects of diphenylhydantoin on synaptic transmission in cat spinal cord and stellate ganglion. J. Pharmacol. Exp. Ther. 120 301-323.

Feng, T. P. (1941) Studies on the neuromuscular junction. XXVI. The changes of the end-plate potential during and after prolonged stimulation. Chin. J. Physiol. 16: 341-372.

Hasbani, M., J. H. Pincus, and S. H. Lee (1974) Diphenylhydantoin and calcium movement in lobster nerves. Arch. Neurol. 31: 250-254.

Hubbard, J. I. (1963) Repetitive stimulation at the neuromuscular junction and the mobilization of transmitter. J. Physiol (Lond.) 169: 641-662.

Katz, B., and R. Miledi (1967) A study of synaptic transmission in the absence of nervc impulses. J. Physiol (Lond.) 192: 407-436

Korey, S. R. (1951) Effect of diphenylhydantoin and mesantoin on the giant axon of the squid. Proc. Soc. Exp. Biol. Med. 79: 297-299.

Lev-Tov, A., and R. Rahamimoff (1980) A study of tetanic and post-tetanic potentiation of miniature end-plate potentials at the frog neuromuscular junction. J. Physiol. (Lond.) 309: 247-273.

Lipicky, R. J., D. L. Gilbert, and I. M. Stillman (1972) Diphenylhydantoin inhibition of sodium conductance in squid giant axon. Proc. Natl. Acad. Sci. U.S.A. 69: 1758-1760.

Magleby, K. L. (1973) The effect of repetitive stimulation on facilitation of transmitter release at the frog neuromuscular junction. J. Physiol. (Lond.) 2.34: $327-352$

Magleby, K. L., and J. E. Zengel (1976a) Augmentation: A process that acts to increase transmitter release at the frog neuromuscular junction. $\mathrm{J}$. Physiol. (Lond.) 257: $449-470$

Magleby, K. L., and J. E. Zengel (1976b) Long-term changes in augmentation, potentiation and depression of transmitter release as a function of repeated synaptic activily at the frog neuromuscular junction. J. Physiol. (Lond.) 257: 471-494.

Mallert, A., and A. R. Martin (1967) An analysis of facilitation of transmitter release at the neuromuscular junction of the frog. J. Physiol. (Lond.) 193: 679-694.

Matsuki, N., F. N. Quandt, R. E. ten Eick, and J. Z. Yeh (1984) Characterization of the block of sodium channels by phenytoin in mouse neuroblastoma cells. J. Pharmacol. Exp. Ther. 228: 523-530.

Matsumoto, H., and C. Ajmone-Marsan (1964) Cortical cellular phenomena in experimental epilepsy. Ictal manifestations. Exp. Neurol. 9: 305-326.

Matsumoto, H., G. F. Ayala, and R. J. Gumnit (1969) Neuronal behavior and triggering mechanisms in cortical epileptic focus. J. Neurophysiol. 32. 688-703.

McLean, M. J., and R. L. Macdonald (1983) Multiple actions of phenytoin on mouse spinal cord neurons in cell culture. J. Pharmacol. Exp. Ther. 227: 779-789.

Meiri, H., S. D Erulkar, T. Lerman, and R. Rahamimoff (1981) The action of the sodium ionophore, monensin on transmitter release at the frog neuromuscular junction. Brain Res. 204: 204-208.

Newman, R. S., and G. B. Frank (1977) Effects of diphenylhydantoin and phenobarbital on voltage-clamped myelinated nerve. Can. J. Physiol. Pharmacol. 55: 42-47.

Parnas, H., and L. A. Segel (1980) A theoretical explanation for some effects of calcium on the facilitation of neurotransmitter release. J. Theor. Biol. 84: 3-29.

Parnas, H., J. Dudel, and I. Parnas (1982) Neurotransmitter release and its facilitation in crayfish: Saturation kinetics of release, and of entry and removal of calcium. Pflugers Arch. 393: 1-14.

Pincus, J. H. (1972) Diphenylhydantoin and ion flux in lobster nerve. Arch. Neurol. 26: 4-10.

Pincus, J. H., and S. H. Lee (1973) Diphenylhydantoin and calcium: Relation to norcpinephrine release in rat brain slices. Arch. Neurol. 29: 239-244.

Prince, D. A. (1968) The depolarization shift in "epileptic" neurons. Exp. Neurol. 21: $467-485$.

Rairles, A., and F. G. Standaert (1966) Pre and post-junctional effects of Dilantin at the cat soleus neuromuscular junction. J. Pharmacol. Exp. Ther. 153: $361-366$

Rosenthal, J. (1969) Post-tetanic potentiation at the neuromuscular junction of the frog. J. Physiol. (Lond.) 203: 121-133.

Schwarz, J., and W. Vogel (1977) Diphenylhydantoin: Excitability reducing action in single myelinated nerve fibres. Eur. J. Pharmacol. 44: 241-249.

Selzer, M.W. (1978) The action of phenytoin on a composite electricalchemical synapse in the lamprey spinal cord. Ann. Neurol. 3: 202-206.

Selzer, M.E. (1979) The effect of phenytoin on the action potential of a vertebrate spinal neuron. Brain Res. 171: 511-521.

Selzer, M. E., G. David, and Y. Yaari (1984) Phenytoin reduces frequency potentiation of synaptic potentials at the frog neuromuscular junction. Brain Res. 304: 149-152.

Sohn, R. S., and J. A. Ferrendelli (1973) Inthibition of $\mathrm{Cd}^{++}$transport into rat brain synaptosomes by diphenylhydantoin (DPH). J. Pharmacol. Exp. Ther. 185: 272-275.

Tuttle, J. B., and $\mathrm{t}$. Richelson (1979) Phenytoin action on the excitable membrane of mouse neuroblastoma. J. Pharmacol. Exp. Ther. 211: 632637

Ward, A. A. (1969) The epileptic neuron: Chronic foci in animals and man. in Basic Mechanisms of the Epilepsies, $\mathrm{H}$. H. Jasper, A. A. Ward, and A. Pope, eds., pp. 263-288, Little, Brown, \& Co., Boston.

Weinrich, D. (1971) Ionic mechanism of post-tetanic potentiation at the neuromuscular junction of the frog. J. Physiol. (Lond.) 212: 431-446.

Willow, M., E. A. Kuenzel, and W. A. Catterall (1984) Inhibition of voltagesensitive sodium channels in neuroblastoma cells and synaptosomes by the anticonvulsant drugs diphenylhydantoin and carbamazepine. Mol. Pharmacol. 25: 228-234.

Yaari, Y., J. H. Pincus, and Z. Argov (1977) Depression of synaptic transmission by diphenylhydantoin. Ann. Neurol. 1: 334-338.

Yaari, Y., J. H. Pincus, and Z. Argov (1979) Phenytoin and transmitter release at the neuromuscular junction of the frog. Brain Res. 160: 479-487.

Yaari, Y., M. E. Selzer, and G. David (1985) Frequency-dependent effects of phenytoin on frog junctional transmission: Presynaptic mechanisms. Brain Res. 338: 177-180.

Younkin, S. G. (1974) An analysis of the role of calcium in facilitation at the frog neuromuscular junction. J. Physiol. (Lond.) 237: 1-14.

Zengel, J. E., and K. E. Magleby (1980) Differential effects of $\mathrm{Ba}^{2+}, \mathrm{Sr}^{2+}$, and $\mathrm{Ca}^{2+}$ on stimulation-induced changes in transmitter release at the frog neuromuscular junction. J. Gen. Physiol. 76: 175-211.

Zengel, J. E., and K. E. Magleby (1981) Changes in miniature endplate potential frcquency during repetitive nerve stimulation in the presence of $\mathrm{Ca}^{2+}, \mathrm{Ba}^{2+}$, and $\mathrm{Sr}^{2+}$ at the frog neuromuscular junction. J. Gen. Physiol. 77: $503-529$ 